\title{
Cholinergic Mechanisms in Generalized Seizures: Importance of the Zona Incerta
}

\author{
Stefan M. Brudzynski, James W. Cruickshank and Richard S. McLachlan
}

\begin{abstract}
Objective: Stimulation of the central cholinergic system results in generalized epileptic seizures. The goal of this study was to map the epileptogenic effects of the cholinergic agonist, carbachol injected into different sites of the basal forebrain and diencephalon of the rat brain. Methods: Carbachol was injected directly into the brain in a dose of 1 or $3 \mu \mathrm{g}$. Seizures were assessed behaviourally on a five-stage scale with electroencephalographic controls. Seizures at stage 1 were the least severe and those at stage 5 the most severe. Results: Injections of high dose carbachol $(3 \mu \mathrm{g})$ induced seizures from $40 \%$ of all injected brain sites. Injections of low dose carbachol $(1 \mu \mathrm{g})$ or isotonic saline into the same brain sites did not cause any behavioural or electrographic seizures. The majority of sites $(84 \%)$ producing generalized seizures (stage 5) were concentrated in or around the zona incerta. Conclusions: Within the anatomical limits of the study, the zona incerta is the area most sensitive to carbachol-induced generalized seizures.
\end{abstract}

RÉSUMÉ: Mécanismes cholinergiques des crises convulsives généralisées: importance de la zona incerta. Objectif: La stimulation du système cholinergique central provoque une crise convulsive généralisée. Le but de cette étude était de cartographier les effets épileptogènes d'un agoniste cholinergique, le carbachol, injecté à différents endroits de la face inférieurs du prosencéphale et du diencéphale de rat. Méthodes: Nous avons injecté une dose de 1 ou $3 \mu \mathrm{g}$ de carbachol directement dans le cerveau. Les crises convulsives étaient évaluées au moyen d'une échelle à cinq niveaux, avec contrôles électroencéphalographiques, le niveau 1 étant les crises convulsives les plus bénignes et le niveau 5 étant les plus sévères. Résultats: L'injection de carbachol à haute dose $(3 \mu \mathrm{g})$ a induit des convulsions originant de $40 \%$ des sites injectés. L'injection de la dose la plus faible de carbachol ( $1 \mu \mathrm{g}$ ) ou d'une solution saline isotonique au niveau des mêmes sites n'a pas causé de crise convulsive observable ou d'anomalie électrographique. La plupart des sites $(84 \%)$ qui ont généré des crises convulsives généralisées (stage 5) étaient concentrés dans ou autour de la zona incerta. Conclusions: Dans les limites anatomiques de cette étude, la zona incerta est la zone la plus sensible aux convulsions généralisées provoquées par le carbachol.

Can. J. Neurol. Sci. 1995; 22: 116-120

Acetylcholinesterase inhibitors, acetylcholine, or acetylcholine analogues are potent epileptogenic agents. ${ }^{1-8}$ Anticholinergic agents, on the other hand, can prevent seizures initiated by cholinomimetics..$^{8-10}$ Seizure activity can be induced by systemic, intraventricular, or intracerebral application of cholinomimetics. ${ }^{1,11-13}$ Direct, cholinergic stimulation can induce seizures from a large number of brain structures including frontal and occipital cortices, deep prepiriform cortex, caudate nucleus, amygdala, hippocampus, and reticular formation. ${ }^{6.10 .11,13-20}$ Susceptibility to seizures differs, however, among different regions, limbic structures being among the most epileptogenic in response to cholinergic stimuli. ${ }^{7.8}$

Basal forebrain and diencephalic areas contribute to the limbic system and were briefly reported to produce seizures when stimulated with carbachol. ${ }^{21.22}$ It is not yet clear, however, which regions within those subdivisions are particularly sensitive to cholinomimetics. An answer to this question will contribute to a better understanding of the mechanism of initiation of generalized seizures and their spread in the brain.
The goal of this study was to map the epileptogenic effects of a cholinergic agonist, carbachol injected intracerebrally into different sites within the basal forebrain and diencephalon to determine if there is a limited region within those parts with particular sensitivity to cholinergic triggering of seizures.

\section{Methods and Materials}

\section{Animals and Surgery}

All the procedures conformed to the guidelines of the Canadian Council on Animal Care. ${ }^{23}$ The study was performed on 45 male Wistar rats weighing 250 - $350 \mathrm{~g}$. Rats were kept in

From the Department of Clinical Neurological Sciences, University of Western Ontario, and Epilepsy Research Laboratory, University Hospital, London.

RECEIVED AUGUST 9, 1994. ACCEPTED IN FINAL FORM NOVEMBER 15, 1994.

Reprint requests to: Dr. S.M. Brudzynski, Department of Clinical Neurological Sciences, University Hospital, P.O. Box 5339, Postal Sin. A, London, Ontario, Canada N6A 5A5 
single cages with a 12:12 hr light:dark cycle and the standard pellet food and water ad libitum. Animals were anaesthetized with Ketamine (40 mg/kg i.m.) /Xylazine (3.2 mg/kg i.m.), placed in a Kopf stereotaxic apparatus, and bilaterally implanted with a stainless steel cannula $(640 \mu \mathrm{m}$, o.d.). Cannulae were placed in a number of brain sites between the following stereotaxic planes: $A=9.5$ to $4.5 \mathrm{~mm}$ from the interaural plane, $\mathrm{L}=$ 0.5 to $3.0 \mathrm{~mm}$ lateral to the midline, and $\mathrm{V}=5.5$ to $9.0 \mathrm{~mm}$ below the surface of the cortex according to the stereotaxic atlas by Paxinos and Watson. ${ }^{24}$ Rats were given a one week recovery period before injections. For other details of animal surgery see Brudzynski et al. ${ }^{25}$

\section{Drugs and Intracerebral Injection Procedure}

Carbachol (carbamylcholine chloride, Sigma Chemical Co., St. Louis, Mo) was dissolved in sterile, $\mathrm{pH}$ controlled saline and was injected unilaterally into the brain by a Hamilton CR 700 microinjector. The drug was given into the brain in a dose of 1.0 or $3.0 \mu \mathrm{g}(5.47$, and $16.41 \mathrm{nmol}$, respectively) in a volume of 0.2 $\mu \mathrm{l}$, and at a rate of $4 \mathrm{nl} / \mathrm{s}$. The low dose of carbachol was below and the high dose above the threshold for seizures $(2.0 \mu \mathrm{g})$ as tested previously for the basal forebrain regions. ${ }^{21}$ This approach potentially enabled identification of brain regions with low and high threshold for seizures. The low volume of injection ensured a limited spread in the tissue (for full discussion $\left.\mathrm{see}^{25.26}\right)$. Injections of $0.2 \mu \mathrm{l}$ of saline served as a control. Injections were made at least one week apart. In total, 90 brain sites were tested in 45 animals. For other details of the injection procedure see Brudzynski et al. ${ }^{25}$

\section{Classification of Seizure Stages and Their Recording}

Animals were observed for 30 minutes after injection in a small padded cage $(25 \times 28 \times 22 \mathrm{~cm}$, high) with a Plexiglas front door. If seizures persisted after that time, animals were injected with sodium pentobarbital $(20 \mathrm{mg} / \mathrm{kg}$ i.p., Somnotol, MTC Pharmaceuticals, Cambridge, Ont). Behavioural seizures were quantitated in a 5-stage scale. 1) Stage 1: twitches of vibrissae associated or followed by increased perioral movements, jaw movements and/or licking and swallowing. 2) Stage 2: eye blinking, ear twitching and head jerking. The tail might be held upward in an " $S$ " shape position. 3) Stage 3: rearing with clonictonic movements of front legs; maintained body balance. 4) Stage 4: rearing and falling backward or sideways with quick regaining of the normal posture. 5) Stage 5: generalized tonicclonic convulsion with accompanying autonomic symptoms such as salivation, urination and defecation; animal remains lying on the ground.

Wet dog shakes (WDS), rapid repetitive shaking of the upper trunk, were also recorded and designated as a separate category.

Stages 1-4 represented various degrees of mild seizures, while stage 5 corresponded to generalized seizures.

Behavioural observations were supplemented with EEG recordings in a group of 19 rats. Stainless-steel wires coated with teflon ( $180 \mu \mathrm{m}$ coated diameter, Medwire, Mount Vernon, N.Y.) were implanted bilaterally on the frontal or parietal cortices and were referenced to the posterior skull. Recordings of EEG were done in freely-behaving animals before and after injection of carbachol (Model 8-10 electroencephalograph, Grass Instrument Co., Quincy, Mass).

\section{Experimental Design}

After the recovery period, animals were adapted to the experimental cage and injected, first with $1 \mu \mathrm{g}$ of carbachol. One week later, $3 \mu \mathrm{g}$ of carbachol was injected into the same brain site. If a seizure did not appear animals were injected with carbachol into the contralateral side of the brain in the same way one week later. If seizures appeared, however, the animals were not injected into the contralateral side. Then, isotonic saline was given into each site one week apart.

\section{Histology}

After completion of the experiment, animals were sacrificed with an overdose of pentobarbital and each injection site was marked with $0.1 \mu \mathrm{l}$ of India ink before perfusion. The brains were perfused transcardially with buffered formalin, removed from the skull and fixed in $10 \%$ formalin. Then, the brains were sectioned with a Leitz freezing microtome for $60 \mu \mathrm{m}$ preparations, air dried and stained with thionine. Maps of injection sites were completed with the aid of a stereomicroscope, (Olympus Optical Co., Japan) equipped with a transmitted light illumination base and drawing attachment (Olympus, SZH-DA). The final composite figures were based on frontal sections of the rat brain according to the stereotaxic atlas. ${ }^{24}$

\section{RESULTS}

\section{Low Dose Carbachol}

Injection of low dose carbachol $(1 \mu \mathrm{g})$ did not induce any seizures or other behavioural epileptic manifestations. Two rats out of 19 with EEG leads had momentary short bouts of immobility accompanied by diffuse synchronized waves in the cortical EEG with a dominating rhythm of $6.8 \pm 0.6 \mathrm{~Hz}( \pm$ S.D., average from 10 samples from the records). These injection sites were localized in the septohypothlamic nucleus and in the bed nucleus of stria terminalis.

\section{High Dose Carbachol}

Injections of high dose carbachol $(3 \mu \mathrm{g})$ into the same brain sites as low doses induced seizures and/or wet dog shakes (WDS) from 36 out of 90 injection sites (28 out of 45 rats). Out of 90 injection sites, seizures were not produced from 54 sites $(60 \%)$, mild seizures of stage 1-4 were produced from 20 sites $(22.2 \%)$, generalized tonic-clonic seizures (stage 5) were induced from 13 sites (14.5\%), and WDS alone (not accompanying other types of seizures) from 3 sites (3.3\%). Injection of 3 $\mu \mathrm{g}$ carbachol induced repetitive behavioural seizures in $88.9 \%$ of seizing rats with an average rate of $7.7 \pm 5.3$ seizures over the 30 min period of observation ( $n=36$, range $1-19$ times) after a single injection. The average duration of single behavioural seizures was $39.7 \pm 35.8 \mathrm{~s}(\mathrm{n}=93$ episodes from 20 rats, range $3-180 \mathrm{~s}$ ).

Out of 19 rats with EEG recordings after injection of $3 \mu \mathrm{g}$ of carbachol, four had overt behavioural seizures and all of them developed high voltage generalized spikes and spike-wave complexes (Figure IA). Eleven rats showed synchronization of cortical rhythms with a dominating frequency of $6.9 \pm 0.7 \mathrm{~Hz}$ ( \pm S.D., average from 22 samples, two from each recording, Figure 1B) without accompanying seizures. Four EEG recordings were without noticeable changes. Rats which did not develop behavioural seizures after $3 \mu \mathrm{g}$ of carbachol, did not show any spikes or other paroxysmal activity in the EEG. 
Localization of all injection sites is illustrated in Figure 2. Injection sites are marked with symbols corresponding to the effects induced by a single injection of $3 \mu \mathrm{g}$ of carbachol. The effects are marked with three categories of symbols: no seizures, mild seizures (stage 1-4) including WDS, and generalized tonicclonic seizures. Injection sites producing WDS and/or seizures of stage 1-4 (23 sites) were scattered throughout the brain and could be found in almost any brain area. However, injection sites producing generalized tonic-clonic seizures (stage 5, 13 sites) were concentrated in a limited area of the brain in or around the zona incerta (Figure 2, filled circles). Out of 13 sites producing severe seizures, $11(84 \%)$ were located in or close to the zona incerta. Analysis of histological preparations points to the zona incerta and its neighbouring thalamic, subthalamic and hypothalamic nuclei (ventromedial thalamic nucleus, ventral posteromedial thalamic nucleus, subincertal nucleus and dorsomedial hypothalamic nucleus) as the most sensitive brain region in producing generalized seizures resulting from cholinergic stimulation, within the investigated limits (injection sites did not reach the prepiriform cortex).

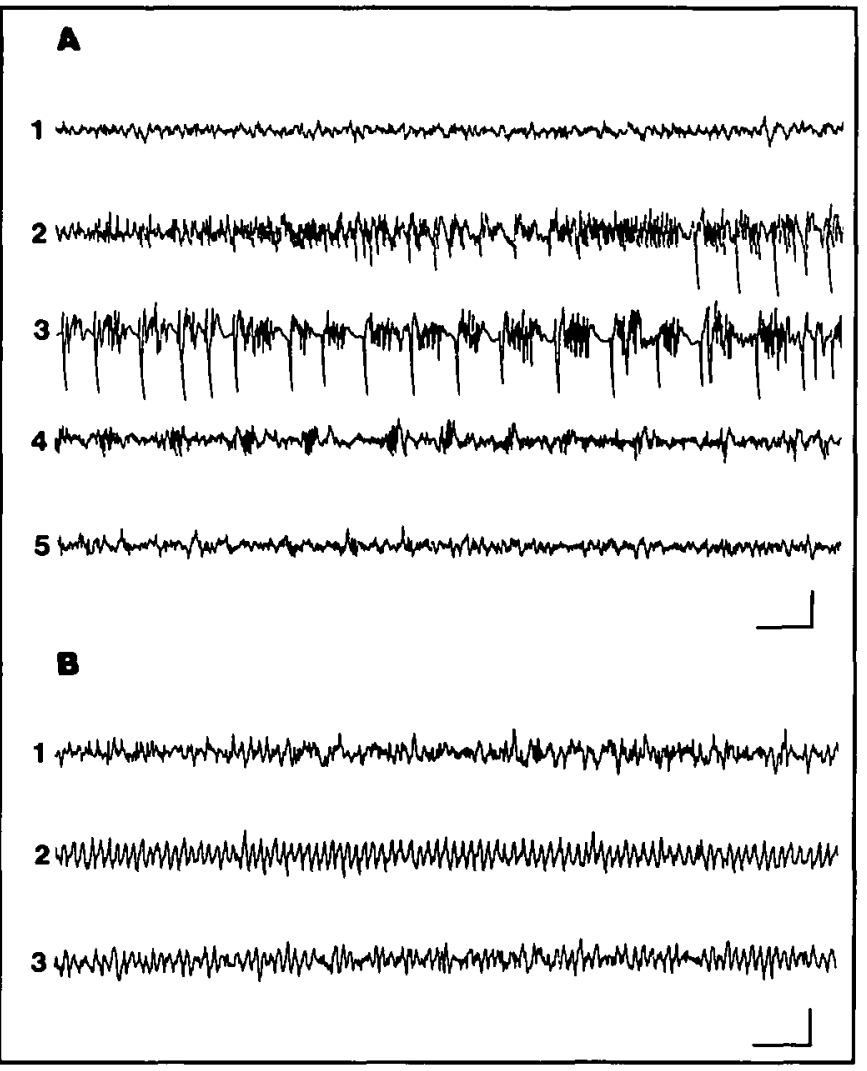

Figure 1: Examples of the EEG recordings from the somatosensory cortex in freely-behaving rat. A: Generalized tonic-clonic seizures were obtained after $3 \mu \mathrm{g}$ carbachol injected into the zona incerta: 1 - electrographic activity before injection, 2 - beginning of seizures 8 min after injection, 3 - fully blown polyspike and wave complexes $60 \mathrm{~s}$ after beginning of seizures, 4, 5 -subsiding of seizures. Calibration: I s and $500 \mu V$. B: Synchronized cortical activity obtained after $3 \mu \mathrm{g}$ carbachol injection into the medial preoptic area: I - electrographic activity before injection, 2 - synchronization 5 min after injection, 3 - beginning of recovery 25 min after injection. Calibration bars: I s and $300 \mu \mathrm{V}$.

\section{Saline Injections}

Isotonic saline injected into the same brain sites as carbachol was without an effect on animal behaviour, regardless whether saline was given one week before or one week after carbachol injection. No observable electrographic change was detected in the EEG.

\section{Discussion}

Direct intracerebral injection of high dose carbachol $(3 \mu \mathrm{g})$ into the basal forebrain and diencephalic areas of the rat brain induced behavioural seizures from $40 \%$ of all injection sites. Injections of low dose carbachol $(1 \mu \mathrm{g})$ or isotonic saline into the same brain sites as high dose carbachol did not cause any behavioural seizures or epileptic changes in the EEG. While injection sites producing minor seizures and WDS were widely scattered, the majority of injection sites associated with generalized tonic-clonic seizures $(84 \%)$ were concentrated in or around the zona incerta and the subthalamus. This observation was corroborated by a negative correlation between stereotaxic frontal or horizontal coordinates and the severity of seizures.

The results are in general agreement with previous studies indicating differential sensitivity of various brain regions to epileptogenic cholinergic stimulation. ${ }^{18.19 .21 .27}$ While some recent studies in experimental epilepsy have focused on the mesencephalic and pontine reticular formation, ${ }^{18.28}$ basal forebrain and diencephalic areas have received less attention. In recent reports, however, low threshold electrical stimulation of the zona incerta induced tonic-clonic seizures, ${ }^{29}$ and cholinergic stimulation of the ventroposterior thalamic nucleus, neighbouring the zona incerta, has also been reported to induce seizures. ${ }^{22}$ The suggestion that the zona incerta may play an important role in the pathophysiology of generalized seizures is also corroborated by lesion studies indicating that electrolytic lesions of the inferior thalamic peduncle, partially including the medial zona incerta, markedly decreased homolateral spike and wave complexes induced by electrical stimulation, or reduced a chlorambucil-induced paroyxsmal electrocortical pattern. ${ }^{30}$

Our finding that the zona incerta is particularly sensitive in triggering generalized seizures after carbachol may be explained by its widespread connections. ${ }^{31.32}$ The zona incerta, which is regarded as a continuation of the midbrain reticular formation extending into the subthalamic region, sends ascending and descending fibres to the reticular structures of the brain stem, precerebellar nuclei, superior colliculus and pretectum, periculomotor nuclei, periaqueductal gray matter, red nucleus, non-specific thalamic nuclei, basal ganglia, hypothalamic structures and substantia innominata. ${ }^{31.32}$ Particularly connections with the reticular formation and structures including nucleus caudatus, entopeduncular nucleus, globus pallidus and putamen nuclei ${ }^{31}$ may explain rapid onset and severity of generalized seizures after carbachol. The substantia innominata to which the zona incerta projects has also been implicated in the pathophysiology of generalized seizures. ${ }^{33}$

Some previous and recent findings have indicated that substrates for generalized seizure induced by GABA antagonists such as pentyleneterazol or bicuculline in the forebrain and in the brainstem are independent. ${ }^{34.35}$ Based on the connectivity, the zona incerta seems to belong to the brainstem seizure 

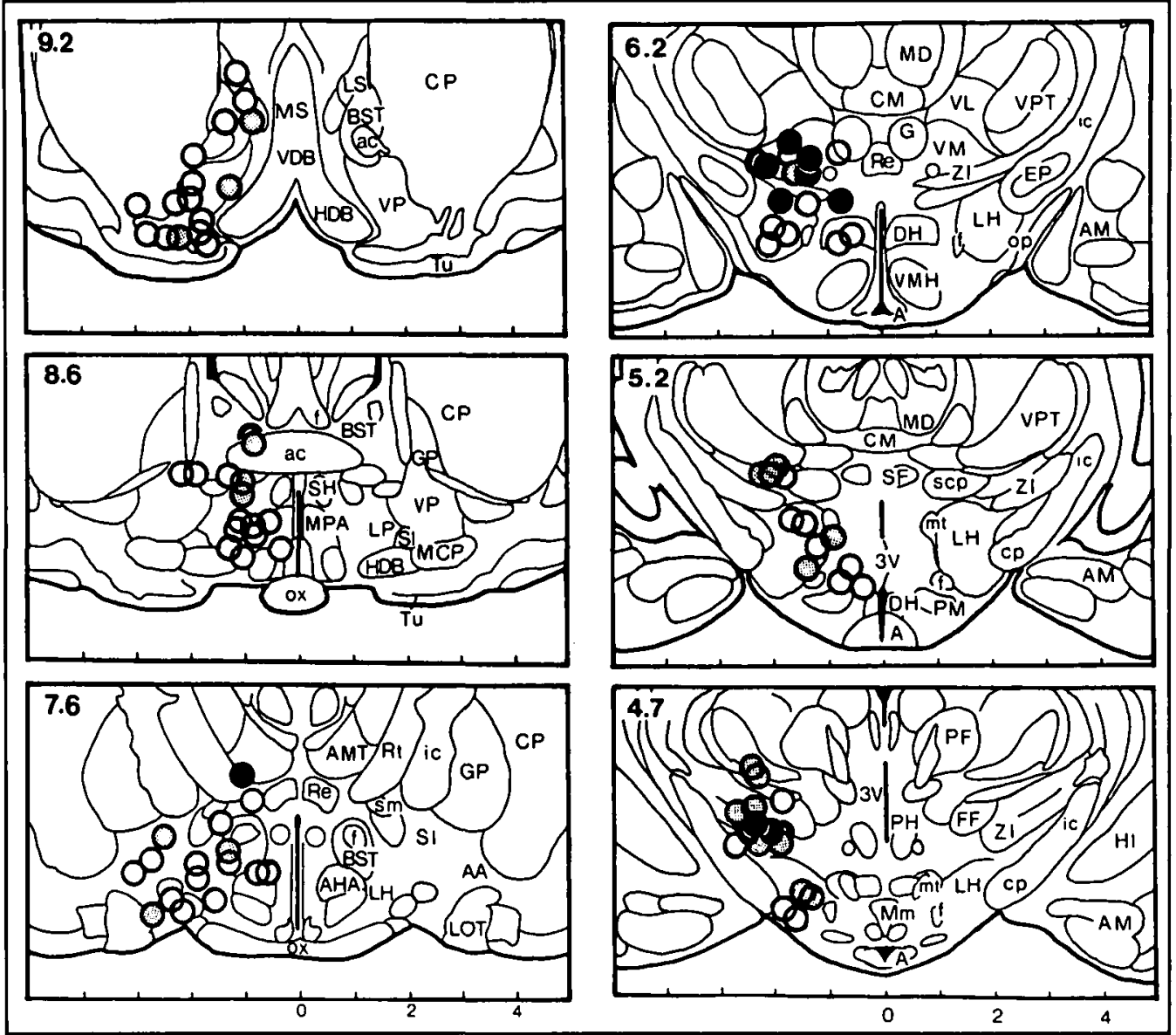

Figure 2: Localization of 90 injection sites (circles) in frontal sections of the rat brain. Frontal stereotaxic planes 9.2 - $4.7 \mathrm{~mm}$ from the interaural line according to the Paxinos and Watson ${ }^{24}$ stereotaxic atlas are marked in the left upper corner of each section. Injection sites are marked with symbols corresponding to the effects induced by a single injection of $3 \mu \mathrm{g}$ carbachol: open circles - no seizures, stippled circles - minor seizures of stage 1 - 4 , filled circles - generalized tonic-clonic seizures of stage 5. Stereotaxic scale in mm. Abbreviations: A - arcuate hypothalamic mucleus, AA - anterior amygdaloid area, ac - anterior commissure, AHA - anterior hypothalamic area, AM - amygdalar complex, AMT - anteromedial thalamic nucleus. BST - bed mucleus of stria terminalis, CM - central medial thalamic nucleus, CP - caudate putamen, cp - cerebral peduncle, DH - dorsomedial hypothalamic nucleus, EP - entopeduncular nucleus, $f$ - fornix, FF - fields of Forel, G - gelatinosus thalamic nucleus, GP - globus pallidus. HDB - horizontal limb of diagonal band, $\mathrm{HI}$ - hippocampal formation, ic - internal capsule, $L H$-lateral hypothalamic area, $L P$ - lateral preoptic area, $L S$ - lateral septal nucleus, LOT - nucleus of lateral olfactory tract, MCP - magnocellular preoptic nucleus, $M D$ - mediodorsal thalamic nucleus, Mm - medial mammillary nucleus, MPA - medial preoptic area, MS - medial septal nucleus, mt-mammillothalamic tract, ox - optic chiasm, op - optic tract, PF parafascicular thalamic nucleus, $P H$ - posterior hypothalamic area, $P M$ - premammillary nucleus, Re - reuniens thalamic nucleus, $R t$ - reticular thalamic nucleus, scp - superior cerebellar peduncle, SF - subparafascicular thalamic nucleus, SH - septohypothalamic nucleus, SI - substantia innominata, sm-stria medullaris, $T u$ - olfactory tubercle, $3 \mathrm{~V}$ - third ventricle, VDB - vertical limb of diagonal band, VL - ventrolateral thalamic nucleus, VM - ventromedial thalamic nucleus, VMH - ventromedial hypothalamic nucleus, VP - ventral pallidum, VPT - ventral posterior thalamic nucleus, ZI - zona incerta.

generating mechanism rather than to the forebrain. It is, however, conceivable that cholinergic epileptogenicity relates to a different neural substrate than seizures induced by GABA antagonists.

Classical anatomic studies have demonstrated a remarkable cholinoceptive field in the region of the zona incerta. ${ }^{36,37}$ Although the zona incerta is much less sensitive to carbachol compared with the deep prepiriform cortex, ${ }^{19}$ our findings suggest that cholinergic terminals in the area of the zona incerta contribute to spread of seizures and to their generalization. Other work in our laboratory has found that the Ml muscarinic receptor subtype is preferentially involved in the mediation of seizures in this region. ${ }^{38}$

\section{ACKNOWLEDGEMENTS}

The study was supported by the Natural Sciences and Engineering Research Council of Canada and the Ontario Mental Health Foundation (S.M.B). The help of Dr. Xiao-Wen Fu is greatly appreciated.

\section{REFERENCES}

I. Beleslin DB, Grbovic L, Radmanovic BZ. The pharmacology of gross behavioural effects of cholinomimetic substances injected into the cerebral ventricles of unanesthetized cats: evidence for central muscarinic mediation. Neuropharmacology 1974; 13: 1163-1169.

2. Beleslin DB, Samardzic R. Comparative study of aggressive behaviour after injection of cholinomimetics, anticholinesterases, nicotine, and muscarinic ganglionic stimulants into the cerebral ventricles of conscious cats: failure of nicotinic drugs to evoke aggression. Psychopharmacology 1979; 60: 147-153. 
3. Cohen SL, Morley BJ, Snead OC. An EEG analysis of convulsive activity produced by cholinergic agents. Prog Neuro-psychopharmacol 1981; 5: 383-388.

4. Lundy PM, Shaw RK. Modification of cholinergically-induced convulsive activity and cyclic GMP levels in the CNS. Neuropharmacology 1983; 22: 55-63.

5. Olney JW, deGubareff T, Labruyere J. Seizure-related brain damage induced by cholinergic agents. Nature 1983; 301: 520-522.

6. Spehlmann R, Daniels JC, Chnag CM. Acetylcholine and the epileptiform activity of chronically isolated cortex. Arch Neurol 1971; 24: 401-407.

7. Turski WA, Cavalheiro EA, Schwarz M, et al. Limbic seizures produced by pilocarpine in rats: behavioural, electroencephalographic and neuropathological study. Behav Brain Res 1983; 9: 315-335.

8. Turski WA, Czuczwar SJ, Turski L, Kleinrok Z. Systemic pilocarpine produces limbic seizures and brain damage in mice. Neurosci Lett 1983; 14: 380S.

9. McDonough JH, Shih T-M. Cholinergic modulation of somaninduced seizures. Soc Neurosci Abstr 1991; 17: 1607.

10. Wasterlain CG, Jonec V. Muscarinic kindling: transsynaptic generation of a chronic seizure focus. Life Sci 1980; 26: 387-391.

11. Grossman SP. Chemically induced epileptiform seizures in the cat. Science 1963; 142: 409-411.

12. Snead OC III. Seizures induced by carbachol, morphine, and leucine-encephalin: a comparison. Ann Neurol 1983; 13: 445-451.

13. Turski WA, Cavalheiro EA, Turski L, Kleinrok $Z$. Intrahippocampal betanechol in rats: behavioural, electroencephalographic and neuropathological correlates. Behav Brain Res 1983; 7: 361-370.

14. Cain DP. Bidirectional transfer of electrical and carbachol kindling. Brain Res 1983; 260: 135-138.

15. Connor JD, Rossi GV, Baker WW. Characteristics of tremor in cats following injections of carbachol into the caudate nucleus. Exp Neurol 1966; 14: 371-382.

16. Decsi L, Nagy J. Chemical stimulation of the amygdala with special regard to influence on the hypothalamus. Neuropharmacology 1974; 13: 1153-1162.

17. Elazar Z. Epileptogenic effects of carbachol microinjected in the brainstem. Soc Neurosci Abstr 1985; 11: 1314.

18. Elazar Z, Feldman Z. Brainstem experimental seizures produced by microinjections of carbachol. Epilepsia 1987; 28: 463-470.

19. Piredda S, Gale K. A crucial epileptogenic site in the deep prepiriform cortex. Nature 1985; 317:623-625.

20. Stivers JA, Skirboll LR, Long R, Crawley JN. Anatomical analysis of frontal cortex sites at which carbachol induced seizures in the rat. Pharmacol Biochem Behav 1988; 30: 129-136.

21. McLachlan RS, Brudzynski SM, Bihari F. EEG and behavioural effects of carbachol in the anterior hypothalamic/preoptic area of the basal forebrain. Epilepsia 1987; 28: 632-633.
22. Mraovitch S, Calando Y, Goadsby PJ, Seylaz J. Cholinergic stimulation of the ventroposterior thalamic nucleus induces limbic seizures: behavioral, ECoG, and metabolic correlates. Soc Neurosci Abstr 1991; 17: 175.

23. Canadian Council on Animal Care, Guide to the Care and use of Experimental Animals, vol. 1, Ottawa, Ontario: CCAC, 1984, 120.

24. Paxinos G, Watson C. The Rat Brain in Stereotaxic Coordinates, 2nd ed., Sydney: Academic Press, 1986.

25. Brudzynski SM, McLachlan RS, Girvin JP. Cholinergically mediated reduction of locomotor activity from the basal forebrain in the rat. Exp Neurol 1989; 105: 197-205.

26. Myers RD. Handbook of Drug and Chemical Stimulation of the Brain. Behavioral, Pharmacological and Physiological Aspects, New York: Van Rostrand-Reinhold, 1974: 759

27. Nashold BS Jr, Gills JP Jr. Chemical stimulation of telencephalon, diencephalon and mesencephalon in unrestrained animals. J Neuropathol Exp Neurol 1960; 19: 580-590.

28. Burnham WM. Core mechanisms in generalized convulsions. Fed Proc 1985; 44: 2442-2445.

29. Gioanni Y, Gioanni H, Mitrovic N. Seizures can be triggered by stimulating non-cortical structures in the quaking mutant mouse. Epilepsy Res 1991; 9: 19-31.

30. Villablanca J, Schlag J, Marcus R. Blocking of experimental spike and wave by a localized forebrain lesion. Epilepsia 1970; 11: 163-177.

31. Kaelber WW, Smith TB. Projections of the zona incerta in the cat, with stimulation controls. Exp Neurol 1979; 63: 177-200.

32. Ricardo JA. Efferent connections of the subthalamic region in the rat. II. The zona incerta. Brain Res 1981; 214: 43-60.

33. McLachlan RS, Bihari F. Secondary generalization of seizures from a cortical penicillin focus following stimulation of the basal forebrain. Exp Neurol 1990; 109: 237-242.

34. Browning R, Maggio R, Sahibzada N, Gale K. Role of brainstem structures in seizures initiated from the deep prepiriform cortex of rats. Epilepsia 1993; 34: 393-407.

35. Magistris MR, Mouradian MS, Gloor P. Generalized convulsions induced by pentylenetetrazol in the cat: participation of forebrain, brainstem, and spinal cord. Epilepsia 1988; 29: 379-388.

36. Jacobowitz DM, Palkovits M. Topographic atlas of catecholamine and acetylcholinesterase-containing neurons in the rat brain. $J$ Comp Neurol 1974; 157: 13-28.

37. Kimura H, McGeer PL, Peng JH, McGeer EG. The central cholinergic system studied by choline acetyltransferase immunohistochemistry in the cat. J Comp Neurol 1981; 200: 151-201.

38. Cruickshank JW, Brudzynski SM, McLachlan RS. Involvement of M1 muscarinic receptors in the initiation of cholinergically induced epileptic seizures in the rat brain. Brain Res 1994; 643: 125-129. 